\title{
MALIGNANT MUCOEPIDERMOID TUMOR ARISING IN THE ACCESSORY PAROTID GLAND : A CASE REPORT
}

\author{
Demetrio Tamiolakis ${ }^{1}$, Vasilios Thomaidis', Ioannis Tsamis ${ }^{2}$, Theodoros Jivannakis ${ }^{3}$, Ageliki Cheva ${ }^{4}$, \\ Nikolas Papadopoulos 4
}

Regional Hospital of Alexandroupolis: Department of Cytology ${ }^{1}$, Department of Maxillofacial Surgery ${ }^{2}$; General Hospital of Drama: Department of Pathology3; Democritus University of Thrace: Department of Histology Embryology 4

Summary: Purpose: The head and neck surgeon's fascination with parotid surgery arises from the gland's spectrum of histopathological presentations, as well as the diversity of its morphological features. A mass arising in the mid-cheek region may often be overlooked as a rare accessory lobe parotid neoplasm. This report serves to revisit the topic of accessory parotid gland neoplasms to emphasize proper management, particularly the surgical aspects, so that consequences of salivary fistula, facial nerve paralysis, and recurrence are avoided. Case report: We report a case of mucoepidermoid carcinoma which was assessed pre-operatively as arising from the accessory parotid gland of a 11-year-old female. She had complained of a painless and round mass of the left cheek for a duration of 12 months. Sialography, ultrasonography, CT scan and MRI were performed preoperatively. Sialography revealed a small duct separating from the Stensen's duct. CT and MRI showed that the tumor with smooth outline was lying on the masseter muscle and detached from the main parotid gland. The preoperative diagnosis was an accessory parotid gland tumor. The tumor was removed without facial nerve injury via standard parotidectomy incision. The tumor was composed of mucous, intermediate and epidermoid cells. The pathological diagnosis was low-grade mucoepidermoid carcinoma. Conclusions: Accessory parotid gland neoplasms are rare and may present as innocuous extraparotid mid-cheek masses. A high index of suspicion, prudent diagnostic skills (including fine-needle aspiration [FNA] biopsy followed by computed tomography [CT] imaging), and scrupulous surgical approach (extended parotidectomy-style incision and limited peripheral nerve dissection when possible) are the keys to successful management of these lesions.

Key words: Accessory parotid gland; Mucoepidermoid carcinoma; Sialography; CT scan; MRI; FNA; Histology

\section{Introduction}

The accessory parotid gland is usually located anterior to the main parotid gland and on the masseter muscle. Histologically it is the same as the main parotid gland. Neoplastic changes can be found in the accessory parotid gland as well as the major salivary glands, however, the accessory parotid tumor is extremely rare. The incidence of this tumor arising in the auxiliary parotid gland ranges from 1 to $7.7 \%$ of all parotid gland tumors $(13,14)$. In previous literature, the frequency of malignant tumors is relatively high as compared with that of main parotid tumors and the reported cases were adults $(6,7,13,14,15)$. In this report, we present a case of a 11-year-old female with mucoepidermoid carcinoma arising in the accessory parotid gland. Computed tomography (CT) sialography and fine-needle aspiration were useful for differential diagnosis of the tumor.

\section{Case report}

A 11-year-old female was sent to our department from another hospital because of a painless and round mass of the right cheek for a duration of 12 months. An ultrasonography showed a well-defined hypoechoic mass on the masseter muscle. A CT scan showed that the tumor was slightly enhanced and located at the anterior aspect of the parotid gland. An MRI also represented a well defined tumor, which showed high intensity on the T2 weighted image. A sialography revealed the secondary duct branching from the Stensen's duct. Fine-needle aspiration was sparsely cellular and composed predominantly of mucin in the background. The mucin was incorrectly interpreted as the myxoid mesenchymal component of pleomorphic adenoma. There were rare epithelial clusters misinterpeted as the epithelial component of pleomorphic adenoma. On high power magnification these cells had a monomorphic 
appearance, round nuclei, small nucleoli and occasional irregular nuclear membranes. There was also another population consisting of cells resembling macrophages (Fig. 1) or having a ductal appearance (intermediate cells) (Fig. 2). A standard parotidectomy incision with superior and inferior extension was performed under general anesthesia and a dissection was performed. The zygomatic and buccal branches of the facial nerve overlying the tumor and Stensen's duct were identified. Adhesion between the nerve branches and the tumor was not seen. The tumor and the remaining accessory gland were removed from the main duct. After surgery, neither facial nerve palsy, nor salivary fistula were found and recurrence has not been seen to the present. The excised tumor was firm and well encapsulated. The cut surface was yellow-grayish. The tissues were fixed in $10 \%$ formalin for light microscopic examinations: the tumor was composed of large mucous cells forming various sized cystic structures, epidermoid cells and cells with an intermediate differentiation between these two cell types (Fig. 3, 4). Nuclear atypia, mitotic activity, and an infiltrative growth pattern were absent. The mucous cells stained positively for periodic acid-Schiff (PAS) (Fig. 5). These features were consistent with a low grade mucoepidermoid carcinoma.

\section{Discussion}

Accessory parotid gland tumor is often noticed as a painless and firm mass in the mid-portion of the cheek. The most common tumor arising in the accessory parotid gland is benign pleomorphic adenoma, followed by mucoepidermoid carcinoma $(6,7,13,14,15)$. These previous data are quite different from the frequency of mucoepidermoid carcinoma in the main parotid glands. There have been rare reports of mucoepidermoid carcinoma arising in the accessory parotid tissues in children as far as we have reviewed (22). The ages at diagnosis in the previous 23 were over 20 years $(6,7,13,14,15)$. The sex difference was described in seven cases; five males and two females and the remaining 16 cases unknown. It is known that mucoepidermoid carcinoma is the most common malignant tumor of the salivary gland before 20 years of age, however, the occurrence in the first decade is extremely rare $(1,2,9,11,17,18)$. Schuller and McCabe (16) described that $57.1 \%$ of the salivary gland tumors in children are malignant and $48.9 \%$ of the malignant tumors are mucoepidermoid carcinoma. Owing to the difference in their prognosis, it is important to cytologically differentiate low-grade mucoepidermoid carcinoma (MEC) from high grade MEC (90\% and $40 \% 5$ year survival, res-

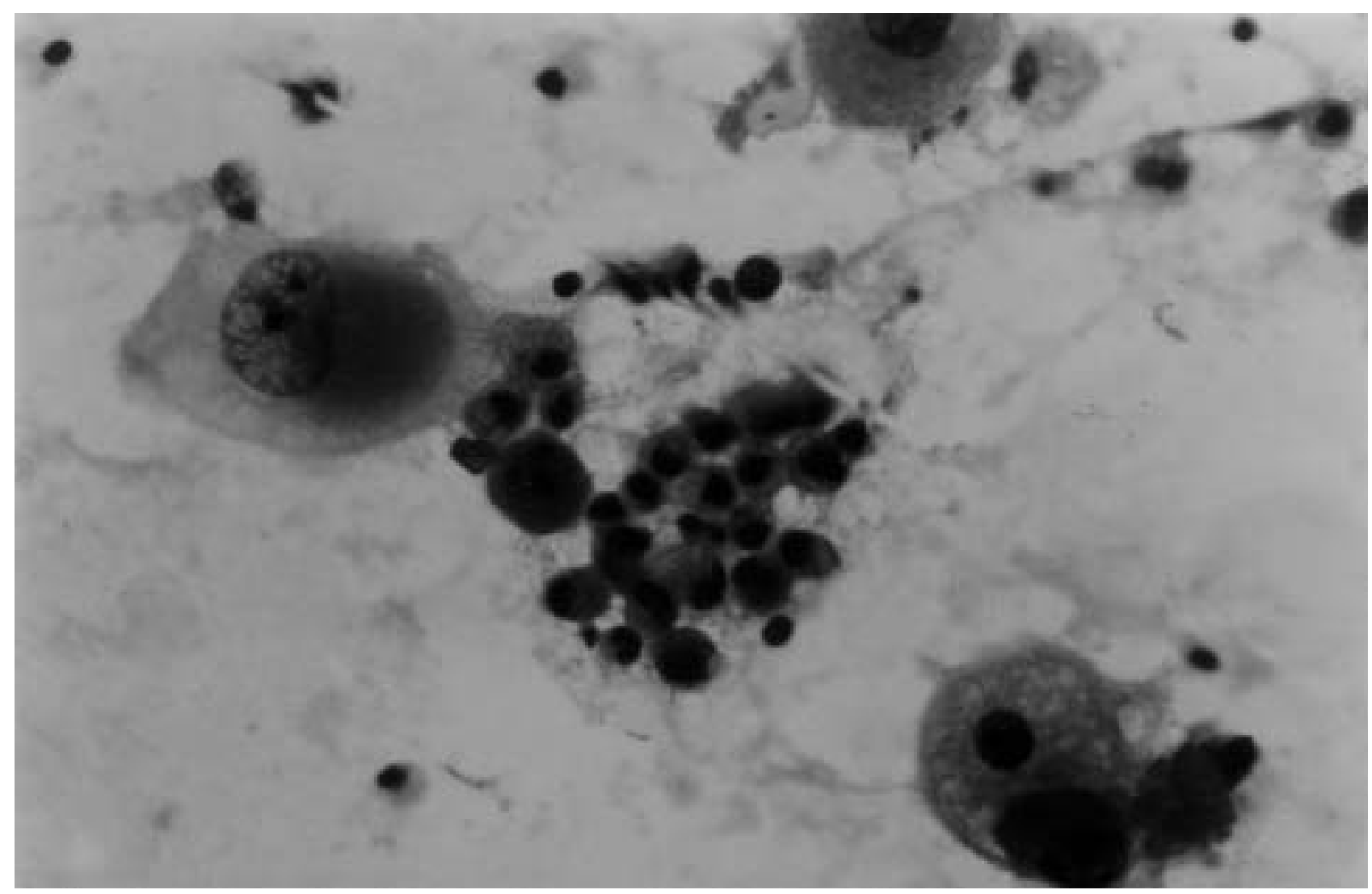

Fig 1: Low-grade MEC: Macrophage-like cells. FNA. Papanicolaou X400. 


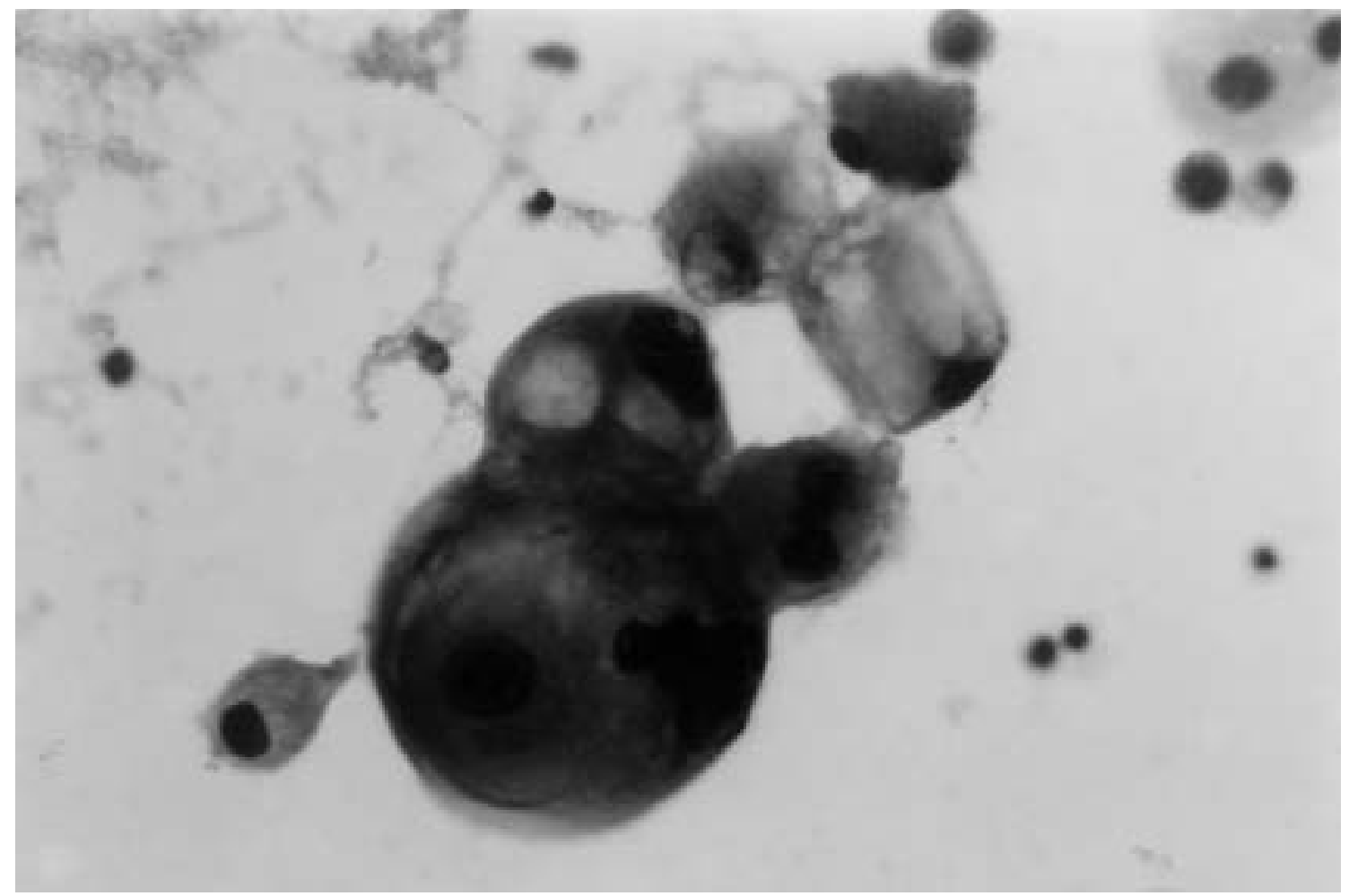

Fig 2: Low-grade MEC: Clustered intermediate cells with some cytoplasmic vacuolation and mild nuclear atypia. FNA. Papanicolaou X400.

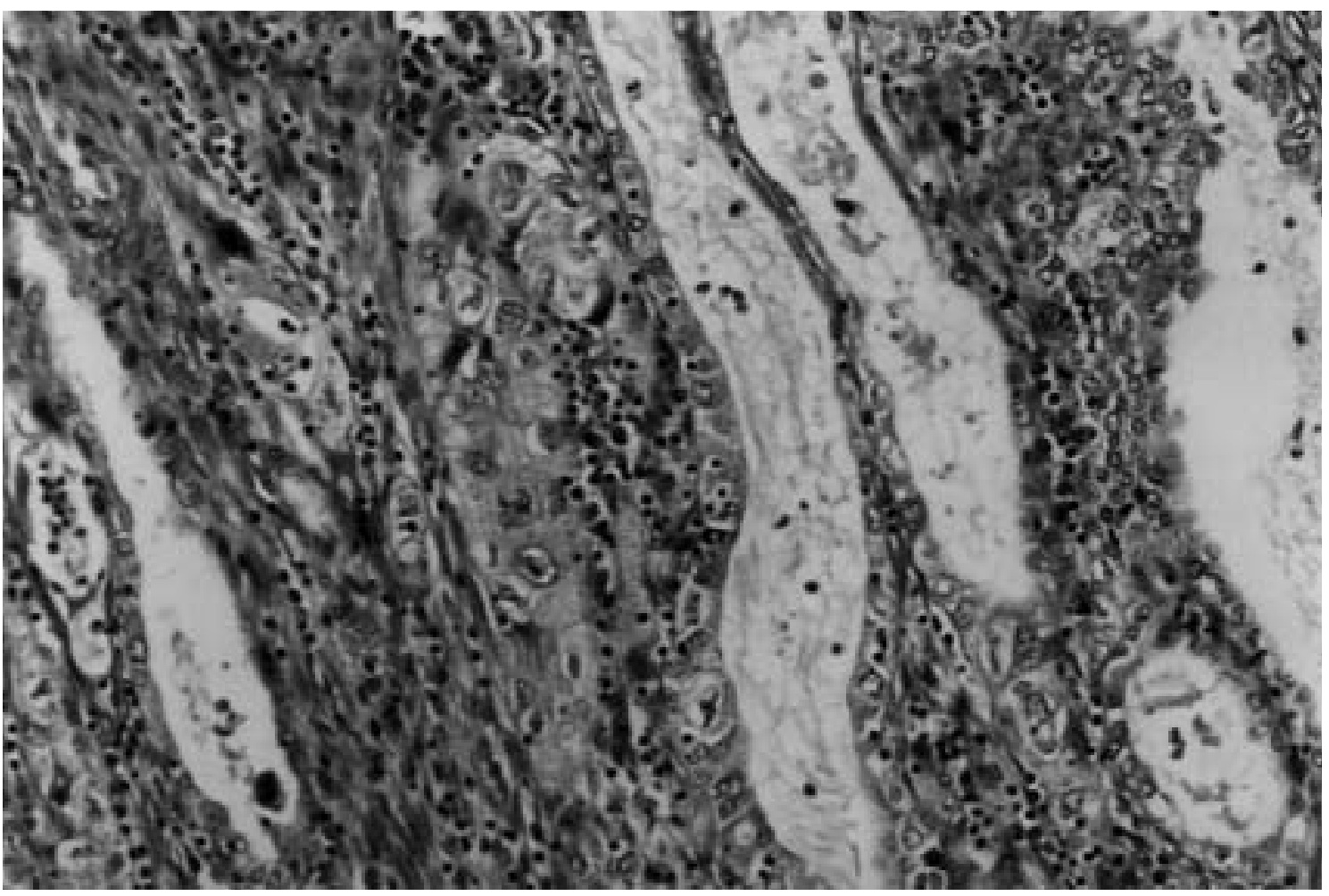

Fig 3: Low-grade MEC: Epidermoid cells, mucus-secreting cells, and cells with an intermediate differentiation between these two cell types. Tissue section H-E X200. 


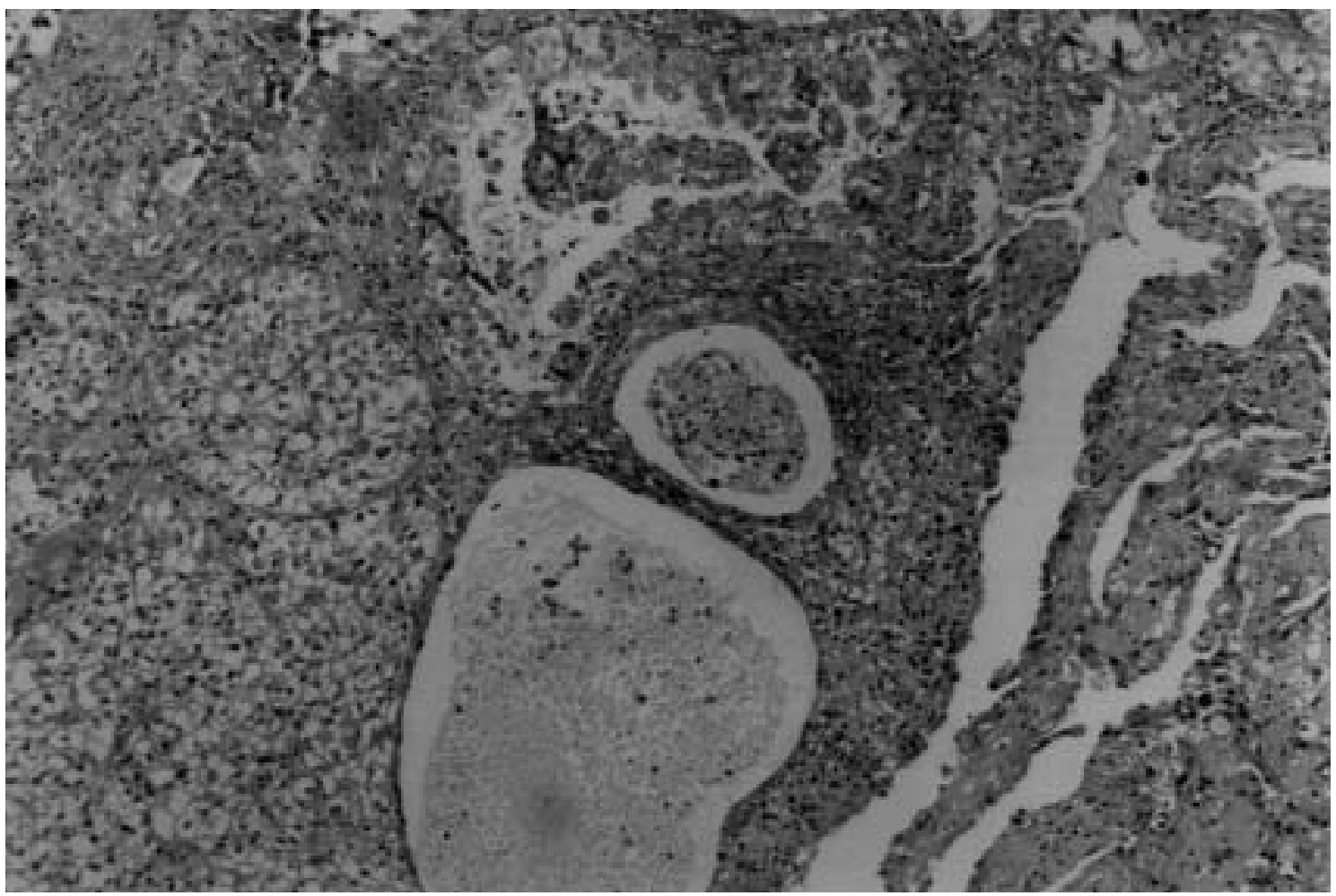

Fig 4: Low-grade MEC: Large mucous cells forming various sized cystic structures. Tissue section H-E X100.

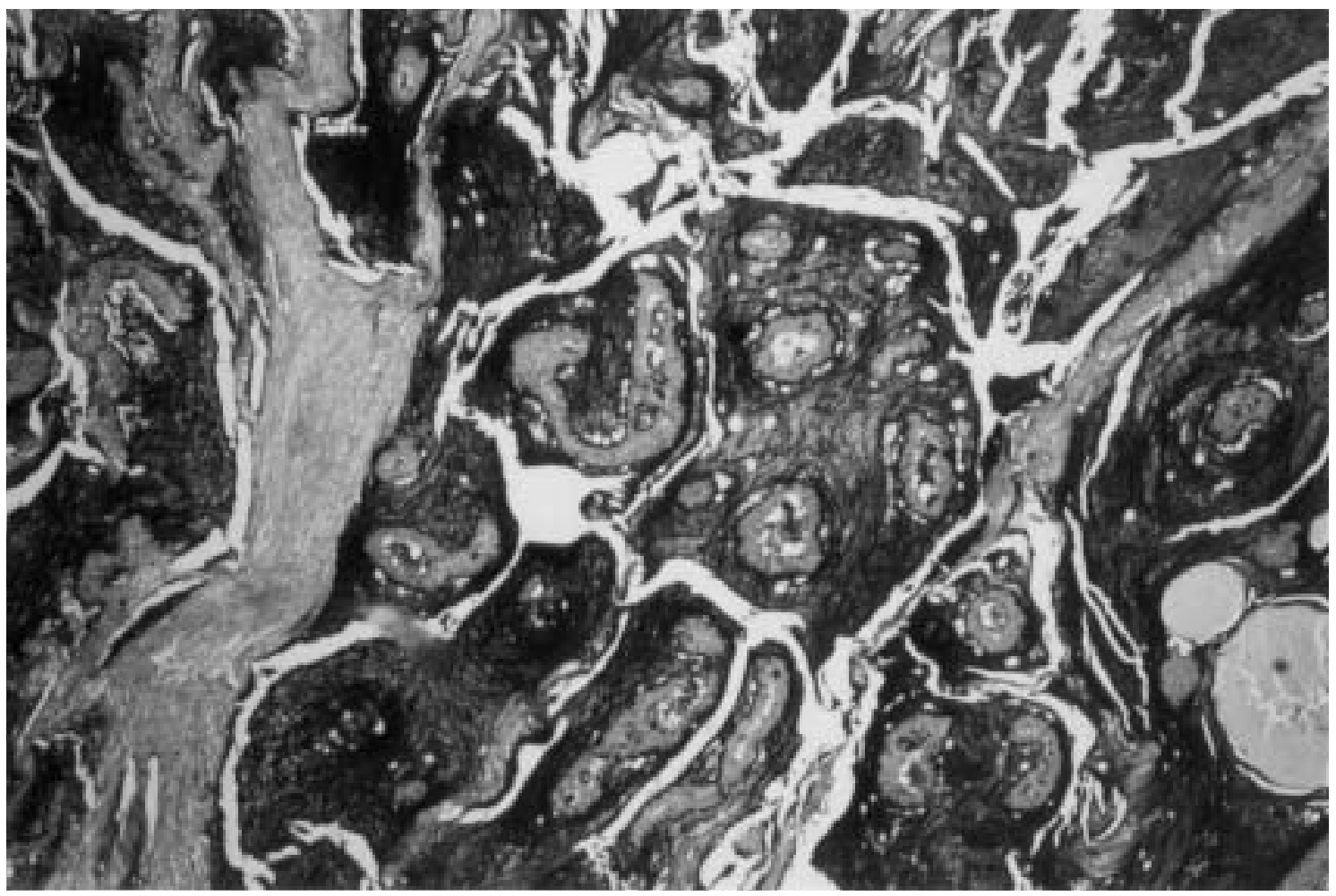

Fig 5: Low-grade MEC: Large mucous cells forming various sized cystic structures. Tissue section PAS X100. 
pectively). Low-grade MEC may be misinterpreted as a benign neoplasm in FNA biopsies because of its bland cytology. Accuracy in the FNA diagnosis of MEC reportedly ranges from 33 to $75 \%$, which is much lower than the overall accuracy of FNA of salivary glands (73-90 \%). Lowgrade MEC is characterized cytologically by admixture of glandular, intermediate, and metaplastic squamous cells. The background may demonstrate mucinous material and tissue debris. Keratinized epidermoid cells are not usually seen. The predominance of the mucin-producing or intermediate cells, with their bland cytology, may be mistaken for the epithelial component of pleomorphic adenoma. The occasional presence of degenerated epithelial cells of ductal origin (cuboidal cells or squamous metaplastic cells) may raise the suspicion of low-grade MEC in such instances $(10,12)$. Polymorphous low-grade adenocarcinoma (terminal duct carcinoma) is difficult to differentiate cytologically from low-grade MEC. This is a low-grade adenocarcinoma arising almost exclusively in the minor salivary glands, particularly those in the palate (5). According to histological features, this tumor is classified into three grades: low-, intermediate- and high-grade malignancy (4). Histologically, the present case was characterized by cystic structures, predominance of mucous cells and abundant extracellular mucin, which indicate a low-grade type. Ultrastructurally, Dardick et al. (3) showed two basic types of cells, luminal and intermediate (nonluminal) cells and the luminal cells evolving to mucus producing cells. In our case, both gobletlike mucous granules and serous granules were found in the luminal cells, which may show that luminal constituent cells possess the potential for bidirectional differentiation.

In the case of accessory parotid tumor, Stensen's duct tumor, intramasseter hemangioma, the anterior extension of main parotid gland tumor, sialolithiasis and heterotopic salivary tumor (20) should be taken into consideration as a differential diagnosis. For preoperative diagnosis, several examinations such as ultrasonography, CT, MRI and sialography were performed in our case and they were useful for a diagnosis by detecting the size, shape and location of the tumor. As the surgical approach to the accessory parotid tumor, usual parotidectomy incision is preferable for preventing injury to the facial nerve and Stensen's duct, in contrast to a direct cheek incision $(6,7,13,14,15)$. The zygomatic and buccal branches of N. VII can be identified by using nerve stimulator and/or microscope without dissection of the facial nerve in the main parotid gland. After surgery, we did not perform adjuvant radiotherapy and chemotherapy. Radiotherapy for mucoepidermoid carcinoma offers no increase in local control or survival among patients receiving complete excision of the tumor (21). Several authors suggested that high-grade mucoepidermoid carcinoma may show a sensitivity to chemotherapy that is similar to squamous cell carcinoma $(8,19)$. It has been reported that the prognosis of mucoepidermoid carcinoma shows better survival rates in younger patients than in those over 60 years and low-grade type is predominantly seen in younger patients (1). We have no prognostic data on this tumor of the accessory parotid gland because of its rarity, therefore, careful and periodical follow-up is recommended.

\section{References}

1. Auclair PL, Ellis GL. Mucoepidermoid carcinoma. Surgical pathology of the salivary glands. In: Major problems in pathology 25 Philadelphia, PA: W.B. Saunders, 1991:269-98.

2. Castro EB, Huvos AG, Strong EW, Foote FW Jr. Tumors of the major salivary glands in children. Cancer 1972;29:312-7.

3. Dardick I, Gliniecki MR, Heathcote JG, Burford-Mason A. Comparative histogenesis and morphogenesis of mucoepidermoid carcinoma and pleomorphic adenoma. An ultrastructural study. Virchows Arch [A] 1990;417:405-17.

4. Foote FW, Frazell EL. Tumors of the major salivary glands. Cancer 1953;6: 1065-133.

5. Frieson HF, Covell JL, Mills SE: Fine needle aspiration cytology of terminal duct carcinoma of salivary gland. Diagn Cytopathol 1987;3:159-62.

6. Ishikawa T, Yasui R, Fujito T. Large retention cysts of the accessory parotid gland associated with a mucoepidermoid tumor in the cyst wall. J Oral Maxillofac Surg 1991;49:884-6.

7. Johnson FE, Spiro RH. Tumors arising in accessory parotid tissue. Am J Surg 1979;138:576-8.

8. Kaplan MJ, Johns ME, Cantrell RW. Chemotherapy for salivary gland cancer. Otolaryngol. Head Neck Surg 1986;95:165-70.

9. Krolls SO, Trodahl JN, Boyers RC. Salivary gland lesions in children. A survey of 430 cases. Cancer 1972;30:459-69.

10. MacLeod CB, Frable WJ: Fine needle aspiration biopsy of the salivary gland: Problem cases. Diagn Cytopathol 1993;9:216-25.

11. Myer C, Cotton RT. Salivary gland disease in children: A review. Part 1: Acquired non-neoplastic disease. Clin Pediatr 1986;25:314-22.

12. Orell SR, Nettle WJS: Fine needle aspiration biopsy of salivary gland tumors: Problems and pitfalls. Pathology 1988;20:332-7.

13. Perzik SL, White IL. Surgical management of preauricular tumors of the accessory parotid apparatus. Am J Surg 1966;112:498-503.

14. Polayes IM, Rankow RM. Cysts, masses and tumors of the accessory parotid gland. Plast Reconstr Surg 1978;64:17-23.

15. Rodino W, Shaha AR. Surgical management of accessory parotid gland tumors. J Surg Oncol 1993;54:153-6.

16. Schuller DE, McCabe BF. The firm salivary mass in children. Laryngoscope 1977;87:1891-8.

17. Seifert G, Okabe H, Caselitz J. Epithelial salivary gland tumors in children and adolescents. Analysis of 80 cases (Salivary Gland Registry 1965-1984). Otorhinolaryngol J 1986;48:137-49.

18. Stern SJ, Suen JY. Salivary gland tumors. Curr Opin Oncol 1993;5:518-25.

19. Suen JY, Johns ME. Chemotherapy for salivary gland cancer. Laryngoscope 1982;92:235-9.

20. Surana R, Moloney R, Fitzgerald J. Tumours of heterotopic salivary tissue in the upper cervical region in children. Surg Oncol 1993;2:133-6.

21. Tran L, Sadian A, Hanson D et al. Major salivary gland tumors: treatment results and prognostic factors. Laryngoscope 1986;96:1139-44.

22. Yoshihara T, Suzuki S, Nagao K. Mucoepidermoid carcinoma arising in the accessory parotid gland. Int J Pediatr Otorhinolaryngol 1999;48:47-52.

Submitted January 2003.

Accepted March 2003.

Nicolaos Papadopoulos,

Assoc. Professor in Histology-Embryology,

Democritus University of Thrace

Dragana, 68100 Alexandroupolis,

Greece.

e-mail:npapad@med.duth.gr 